\title{
Development of a multi-adaptive feeding device for automated plug seedling transplanter
}

\author{
Yuanyuan Shao ${ }^{1,2}$, Xiang $\mathrm{Han}^{1}$, Guantao Xuan ${ }^{1 *}$, Yi Liu¹, Chong Gao', \\ Gongpu Wang ${ }^{2}$, Zhichao $\mathrm{Hu}^{2 *}$ \\ (1. College of Mechanical and Electrical Engineering, Shandong Intelligent Engineering Laboratory of Agricultural Equipment, \\ Shandong Agricultural University, Tai'an 271018, Shandong, China; \\ 2. Nanjing Institute of Agricultural Mechanization, Ministry of Agriculture and Rural Affairs, Nanjing 210014, China)
}

\begin{abstract}
In order to improve the adaptability of the seedling feeding devices to different plug trays for various seedlings, a multi-adaptive plug seedling feeding device for automatic field transplantation was developed. Its efficiency and adaptability have been improved using a seedling delivery device equipped with a row of end-effectors, which were provided with continuous plug seedlings by a compact seedling tray conveyor carrying out a reciprocating action. Each operation for the seedling feeding device could work automatically through a control system. Three categories of plug seedlings, cucumber, pepper and tomato seedlings were tested. The results of the performance test for the prototype demonstrated that the best performance emerged in the cucumber seedlings in 50-cell trays with the highest success rate of $88 \%$ at the feeding frequency of 6 groups/min. The lowest success rate was $73.33 \%$ for the tomato seedlings in 105-cell trays at the feeding frequency of 12 groups/min. It can be concluded that the automated feeding device developed in this study could be used for various plug seedlings as a result of its strong adaptability.
\end{abstract}

Keywords: plug seedling, automated feeding device, vegetable transplanting, control system

DOI: $10.25165 /$ j.ijabe.20211402.6003

Citation: Shao Y Y, Han X, Xuan G T, Liu Y, Gao C, Wang G P, et al. Development of a multi-adaptive feeding device for automated plug seedling transplanter. Int J Agric \& Biol Eng, 2021; 14(2): 91-96.

\section{Introduction}

Plug seedling for transplantation is an effective planting method widely used in vegetable production to promote crop growth and increase vegetable yield $\mathrm{d}^{[1,2]}$. As the largest producer and consumer of vegetables in the world, there is a rapidly increased demand for plug seedlings in China ${ }^{[3,4]}$. However, plug seedling transplanting depends extensively on manual labor with high labor intensity and low production efficiency. Even though plug seedlings can be planted using a semi-automatic transplanter, while other operations including seedling pick-up and dropping seedling are still performed manually, which results in low transplanting speed and high labor cost ${ }^{[5-7]}$. To deal with these, it is necessary to develop an automated feeding device for the transplanter with high efficiency, low dependence on labor and low cost. Compared with bare-root plants, plug seedlings are more suitable for automated feeding due to the uniform size, shape and

\section{Received date: 2020-07-07 Accepted date: 2020-09-11}

Biographies: Yuanyuan Shao, PhD, Associate Professor, research interests: agricultural mechanization, Email: syy007@sdau.edu.cn; Xiang Han, Master candidate, research interests: agricultural mechanization, Email: 1013320898@qq.com; Yi Liu, Master candidate, research interests: agricultural mechanization, Email: 906157621@qq.com; Chong Gao, Master candidate, research interests: agricultural mechanization, Email: 1092601973@qq.com; Gongpu Wang, MS, Assistant Professor, research interests: agricultural machinery design, Email: wanggongpu37@163.com.

*Corresponding author: Guantao Xuan, $\mathrm{PhD}$, Associate Professor, research interests: agricultural mechanization. Shandong Agricultural University, Tai'an 271018, China. Tel: +86-538-8249831 Email: xuangt@sina.com; Zhichao Hu, PhD, Professor, research interests: agricultural mechanization engineering. Nanjing Institute of Agricultural Mechanization, Ministry of Agriculture and Rural Affairs, Nanjing 210014, China. Tel: +86-25-84346246, Email: zchu369@163.com. location ${ }^{[8]}$. Armstrong et al. ${ }^{[9]}$ invented a plug seedling ejection mechanism to provide the orderly arrangement of plug seedlings for automatic transplantation. Ting et al. ${ }^{[10,11]}$ incorporated a sliding-needle sensor gripper into the robot for picking up the seedlings with different shapes and sizes, which was not popularized due to complicated structure and low efficiency. Italian Ferrari Company developed a full-automatic transplanter to fulfill all the operations including seedling pick-up, delivery, separation and planting. But operation stability was poor and seedlings were crowded seriously in the process of separation and planting ${ }^{[12]}$. Moreover, Hd144 type automatic transplanter in Australia and another automatic transplanter manufactured by Pearson Company in the UK are complicated and giant, these were incapable of coping with the small and scattered planting conditions in China ${ }^{[13,14]}$.

Recent research with robotic technology for an automated feeding device of the transplanter has been greatly promoted in China ${ }^{[15-19]}$. Ye et al. ${ }^{[20]}$ studied and developed a cam mechanism with a seedling pick-up arm for vegetable pot seedling transplanter. There were also some shortcomings such as poor operational stability, complex structure and high manufacturing cost. Han et al. ${ }^{[21]}$ designed a pincette-type end-effector with two fingers and four pins for picking up seedlings. It did great harm to seedling pot while automatically picking up seedlings. $\mathrm{Wu}$ et al. $^{[22]}$ developed a seedling conveying device with a recognition system for seedlings using machine vision technology. It could reduce the seedling missing, but the efficiency is still low by single plug detection. Yang et al. ${ }^{[23]}$ designed the seedling cups with reciprocating movement to pick up and drop the seedlings, which improved operating efficiency and automation of plug seedlings transplanting system. These devices have poor performances in 
flexibility and adaptability for various seedlings and different plug trays $^{[14,24,25]}$.

The present study focuses on developing a multi-adaptive feeding device to perform the groups of seedlings pick-up and dropping for the automated transplanter. A seedling delivery device equipped with a row of end-effectors was developed to improve the adaptability for various seedling trays and operation efficiency.

\section{Mechanical structure design}

\subsection{Structure overview}

A functional model of the automated feeding device using the SolidWorks 2016 SP1.0 (Dassault Systemes S.A, Massachusetts, America) is shown in Figure 1. It was comprised of a plug seedling delivery device, a seedling tray conveyor, and end-effectors. Plug seedling delivery device was driven by a stepper motor to make reciprocating movements between plug tray and chain cups. After picking up a group of seedlings from plug tray, plug seedling delivery device returned and stop at the dropping seedling position by triggering the photoelectric switch. End-effectors opened and dropped the seedlings as a result of the cylinder operation. When all the seedlings have been picked up, the seedling tray conveyor was driven by a stepper motor to transport the seedling tray. There was adjustable spacing between the end-effectors to improve its adaptability for various seedlings and different plug trays.

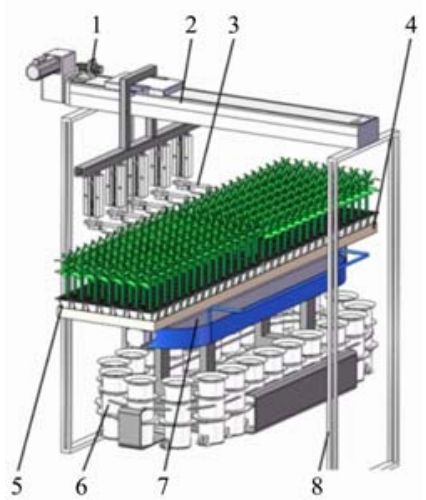

1. Photoelectric sensors 2. Plug seedling delivery device 3. End-effector

4. Pallet of plug tray 5. Plug tray 6. Chain cups 7. Seedling tray conveyor 8. Support frame

Figure 1 Functional model of the automated feeding device

\subsection{Design of plug seedling delivery device}

As shown in Figure 2, the plug seedling delivery device was composed of a linear guide rail, stepper motor, 'I' shaped connector, ' $\mathrm{T}$ ' shaped chute, rack, double-axle telescopic cylinder, cylinder claws, U-type auxiliary gripper, photoelectric sensor. The cylinder claws and double-axle telescopic cylinder were hung on the rack by the 'I' shaped connector fixed with the ' $T$ ' shaped chute in rack. The rack could move along the linear guide rail installed on frame. Consequently, the plug seedling delivery device accomplished the reciprocating motion between the seedling tray and chain cups. Cylinder claws connected with the double-axle telescopic cylinder could move up and down, or open and close with a U-type auxiliary gripper.

\subsection{Design of seedling tray conveyor}

The seedling tray conveyor automatically provided rows of seedlings on the path of seedling pick-up at all times, which was designed to have a simple and compact structure. As shown in Figure 3, seedling tray conveyor was composed of linear guide rail, stepper motor and pallet of plug tray. Driven by stepper motor, two seedling trays placed in the pallet of the plug tray moved back and forth in a linear manner, and the vacant tray could also be easily replaced. When groups of seedlings have been picked up at the designed position, seedling tray conveyor made one movement in accordance with seedling pick-up.

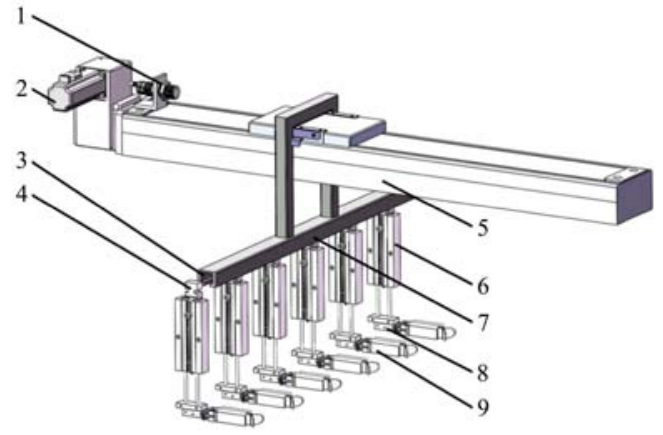

1. Photoelectric sensor 2. Stepper motor 3. 'T' shaped chute 4. 'I' shaped connector 5. Line-glide rail 6. Double-axle telescopic cylinder 7. Rack 8. Cylinder claw 9. U-type auxiliary gripper

Figure 2 Structure of plug seedling delivery device

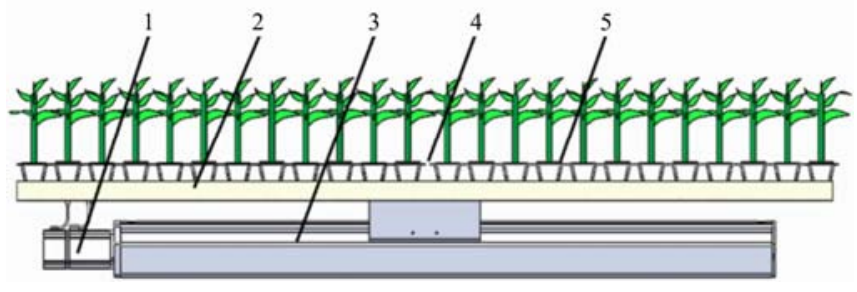

1. Stepper motor 2. Pallet of plug tray 3 . Linear guide rail 4. Plug tray A 5. Plug tray B

Figure 3 Structure of seedling tray conveyor

\subsection{Design of end-effector}

As an important component, the end-effector not only held the seedlings firmly but also minimized damage to the seedlings. As shown in Figure 4, the end-effector was composed of a cylinder claw and a U-type auxiliary gripper.

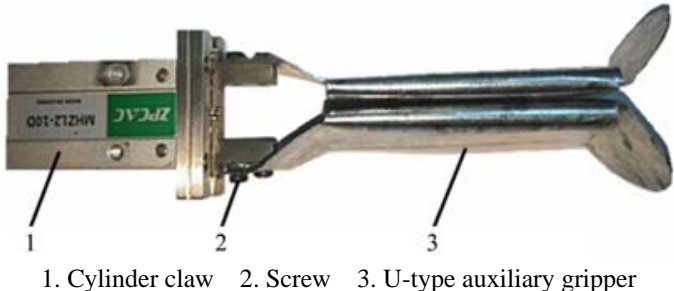

Figure 4 Structure of end-effector

There was an 'I' shaped connector installed on the upper part of the cylinder through bolts and nuts as shown in Figure 5. The end-effector was reliably attached to the rack as the result of ' $\mathrm{I}$ ' shaped connector fixed in the ' $\mathrm{T}$ ' shaped chute with set screw. With such special structure, spacing between end effectors could be adjusted arbitrarily to meet the different specifications of plug tray.

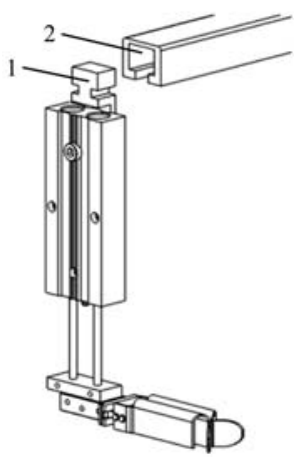

1. 'I' shaped connector 2. ' $T$ ' shaped chute

Figure 5 Structure of spacing adjusting device 


\section{Operation programs and motion planning}

\subsection{Operation principle}

The seedling delivery device was equipped with a row of end-effectors and used for picking up and dropping the seedlings in groups. As shown in Figure 6, picking seedlings at one or two gap is to avoid the mutual interference between adjacent end-effector mechanisms. Six plug seedlings were fed to chain cups for 72-cell tray at one time (Figure 6b), and five plug seedlings were fed for 50- and 105-cell tray at one time (Figures 6a and 6c).
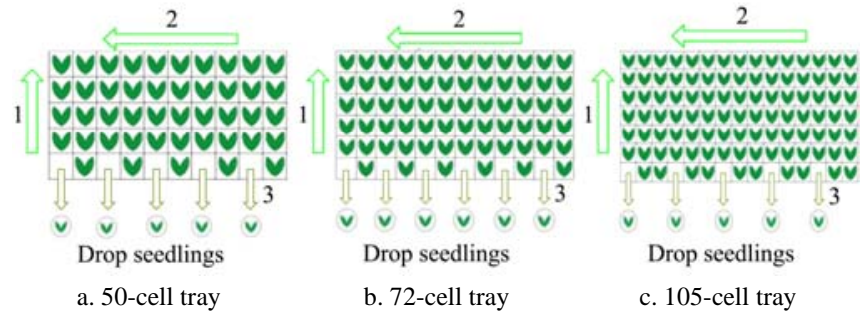

1. Moving direction of plug seedling delivery device 2. Moving direction of seedling tray conveyor 3 . Operation of dropping seedlings

Figure 6 Operation principle for the automated feeding device
Driven by stepper motor and cylinder, seedling delivery device moved back and forth in a linear manner over the seedling tray conveyor. The operation process is as follows in detail.

S1: Driven by double-axle telescopic cylinder, end-effectors protruded and U-type auxiliary gripper opened for seedling pick-up (Figure 7a)

S2: Seedling delivery device executed linear motion by stepper motor and line-glide rail until plug seedlings entered the U-type auxiliary gripper (Figure 7b).

S3: When "U" type auxiliary grippers closed under the control of PLC, a group of plug seedlings were caught on their stems (Figure 7c)

S4: Seedling delivery device retracted and move backward to the seedling feeding position when stepper motor started again (Figure 7d).

S5: Stepper motor stopped and double-axle telescopic cylinder started under the control of PLC, end-effectors protruded and opened. A group of seedlings was dropped in chain cups. Plug seedling delivery device waited for the next seedling delivery (Figures 7e-7f)

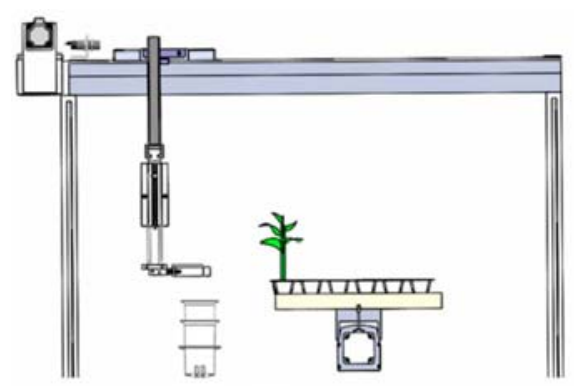

a. Start feeding seedlings

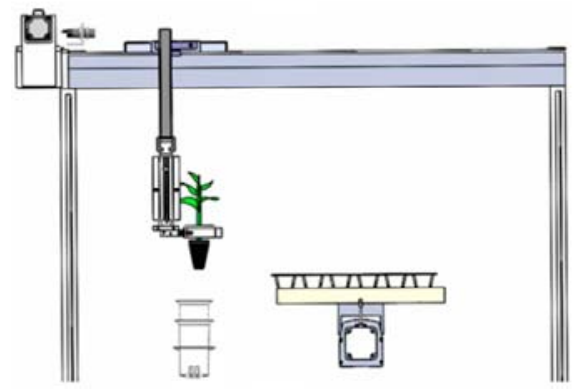

d. Seedlings delivery

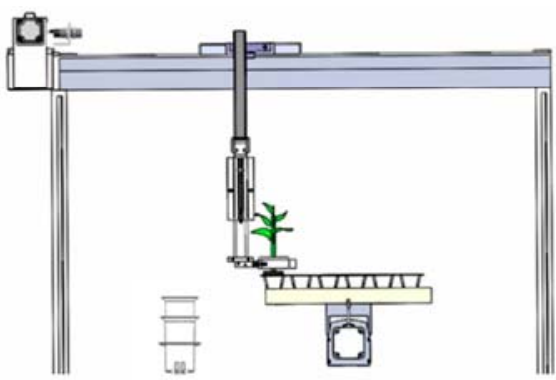

b. Catch seedlings

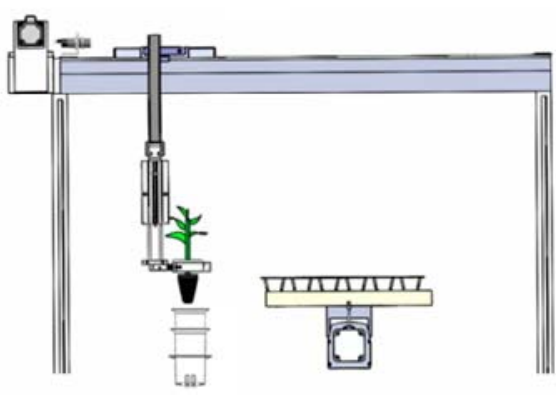

e. Drop seedlings

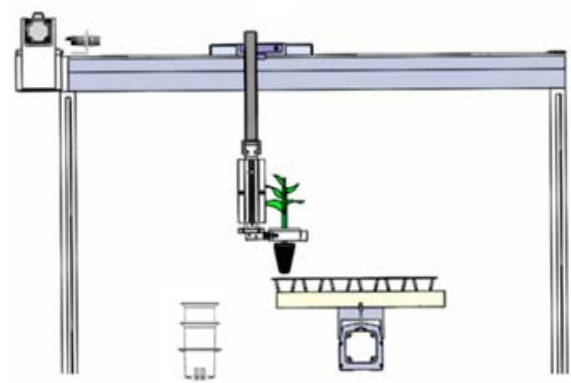

c. Seedlings pick-up

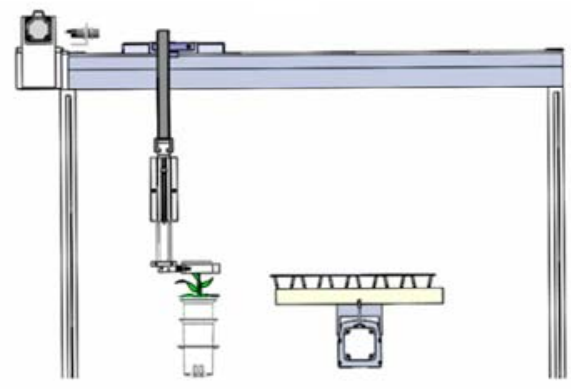

f. Finish feeding seedlings

Figure 7 Delivery process of plug seedlings

\subsection{Operation schedule of seedling tray conveyor}

Seedling tray conveyer was designed to provide the plug seedlings for delivery device. In the case of six seedlings being picked up from the 72-cell plug tray at one time, operation schedule of seedling tray conveyer is shown in Figure 8.

S1: After the seedlings at the position shown in Figure 8a have been picked up, seedling tray conveyer moved left one plug for the remaining seedlings pick-up as shown in Figure 8b.

S2: When all the seedlings have been picked up from one tray, another seedling tray was transported from the right to the fixed position as shown in Figure 8c. Meanwhile, the vacant tray was replaced with one new seedling tray as shown in Figure 8d.

S3: After all the seedlings in the tray have been picked up again, the seedling tray conveyer moved right thirteen plugs for the next operation cycle as shown in Figure 8e. Similarly, the vacant tray on the right was replaced by the new one as shown in Figure $8 f$.

\section{Control system design}

\subsection{System structure and control principle}

An integrated control system was designed using a program controller FX1N-24MT-001A in accordance with each operation of the seedling feeding device. Specifically, the pneumatic control method was used for seedling pick-up and drop, and seedling delivery and tray transport were managed through electronic control means. All these operations cooperated with control elements such as photoelectric sensor, solenoid valve, DM542 stepper motor driver, touch screen, etc.

\subsection{Control flow design}

As shown in Figure 9 (in the case of 72-cell tray), the control flow chart for the automated feeding device was illustrated as follows.

S1: When the control system was activated, PLC sent a signal to control the forward rotation of the stepper motor, then the 
seedling delivery device would move to assigned position for picking up seedlings at intervals by cylinder claws closing and double-axle telescopic cylinder retracting, which was controlled by PLC.

S2: PLC instructed the stepper motor to rotate backward and seedling delivery device returned to the seedling dropping position. Photoelectric sensor was triggered and sent a signal to the PLC. Then stepper motor stopped and cylinder claw drove the U-type auxiliary gripper to open and plug seedlings dropped into chain cup. Single operation cycle for seedling feeding was finished.

S3: During the operation cycles, seedling tray conveyer would move specific number of plug for feeding the remaining seedling of one tray as the result of counter control. All the seedlings in one tray were fed by several operations in this way.

S4: PLC sent a signal to change the rotation direction of the stepper motor, a new seedling tray would be transported to replace the vacant tray by seedling tray conveyor reciprocating movement.

The automated feeding device could feed plug seedlings into chain cups constantly by carrying out these operations periodically.

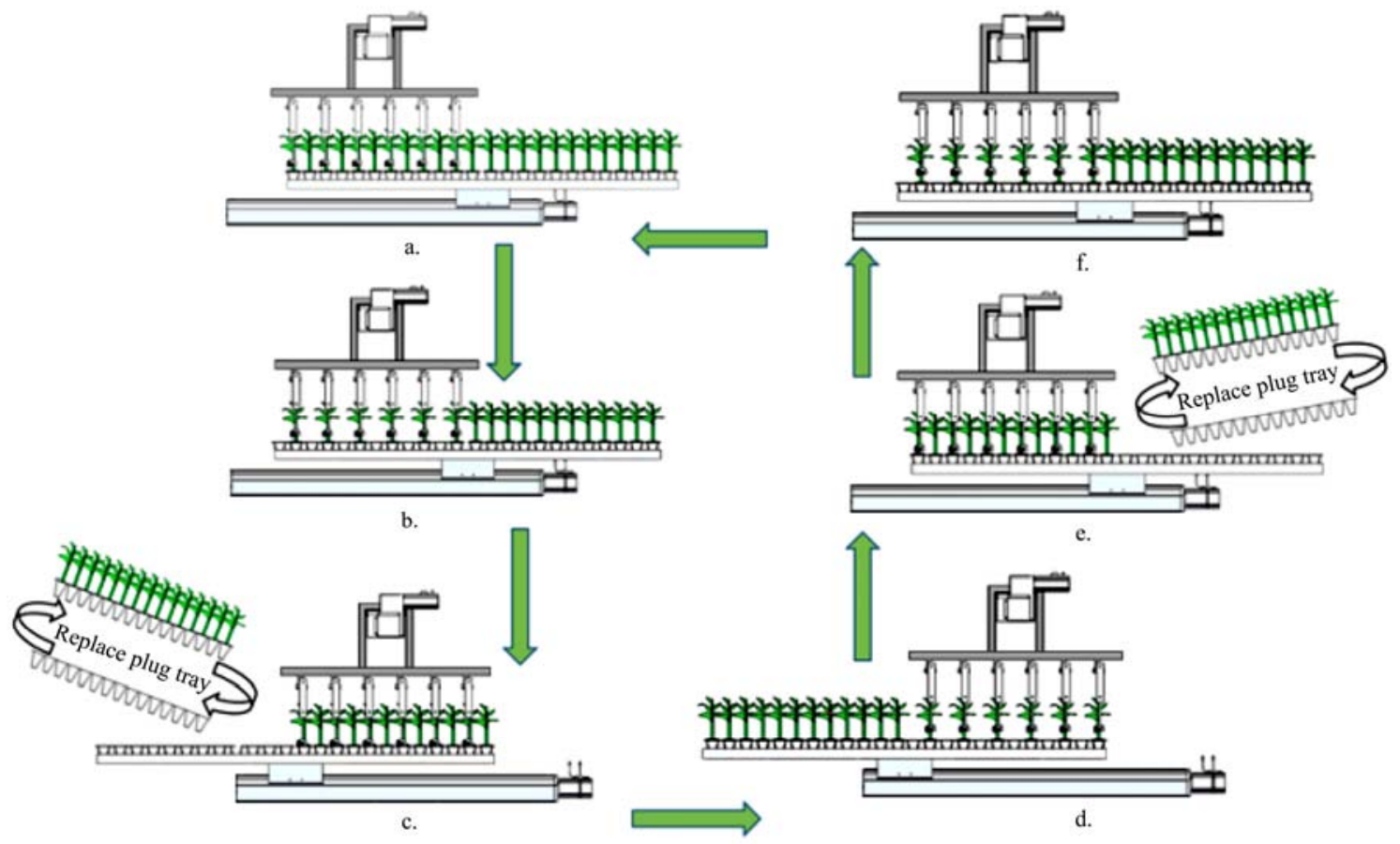

Figure 8 Operation schedule of seedling tray conveyor in term of the 72-cell tray

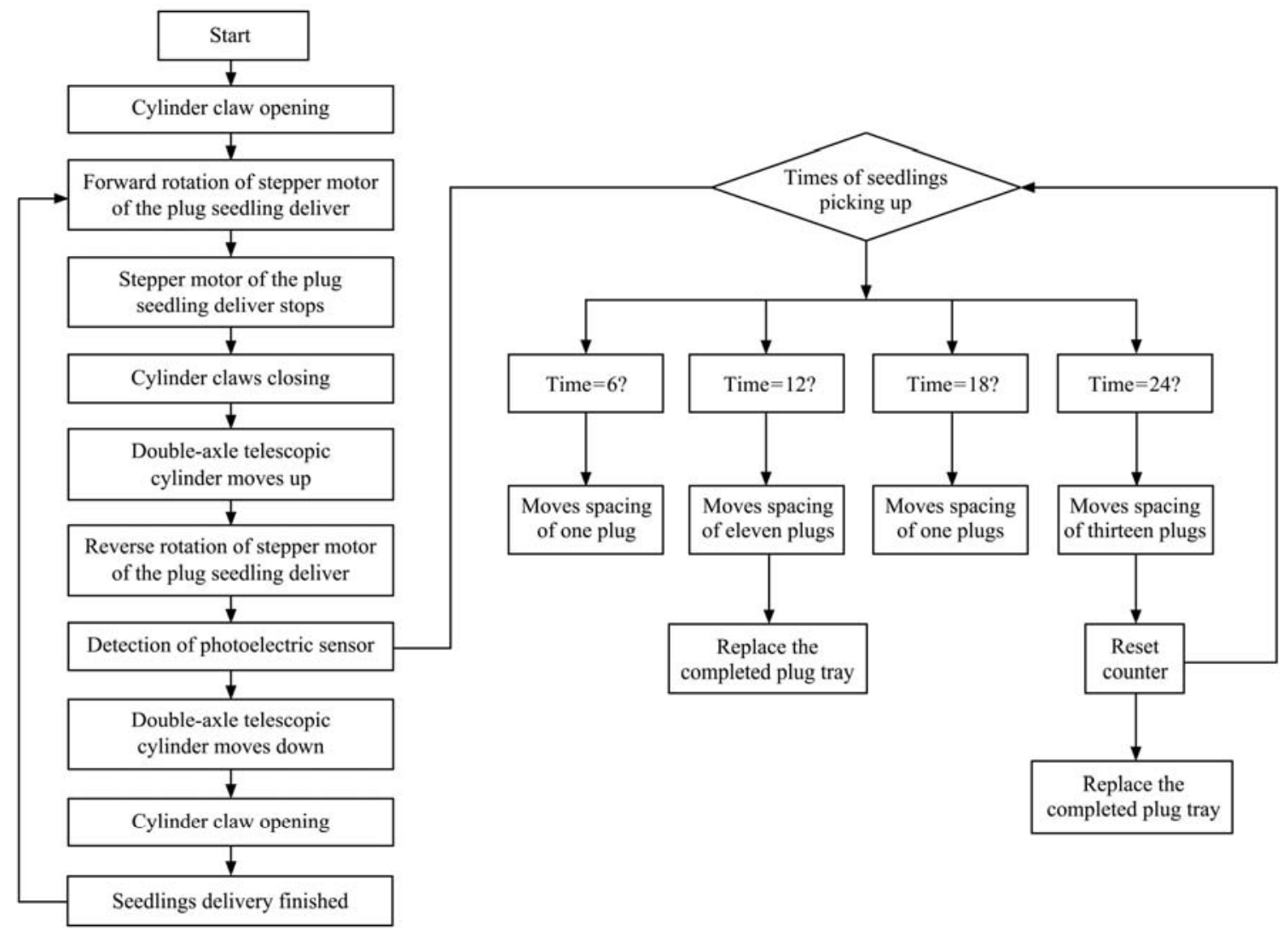

Figure 9 Control flow of automated feeding device 


\section{Performance test}

\subsection{Test design}

A prototype of the automated feeding device for seedlings in groups was manufactured to test its performance at different feeding frequency. As shown in Figure 10, seedling feeding test was conducted in May 2019 in the laboratory at Shandong Agricultural University, Tai'an City, Shandong Province, China. There were three categories of seedlings (Figure 11), two trays for each seedling, used for feeding test, i.e., 35-day-old cucumber seedlings in 50-cell trays, 30-day-old pepper seedlings in 72-cell trays, 38-day-old tomato seedlings in 105-cell trays. Physical and mechanical properties of the seedlings are shown in Table 1. Before the performance test, end-effectors were installed correctly and fixed at a regular spacing to meet the feeding requirement of various plug trays.

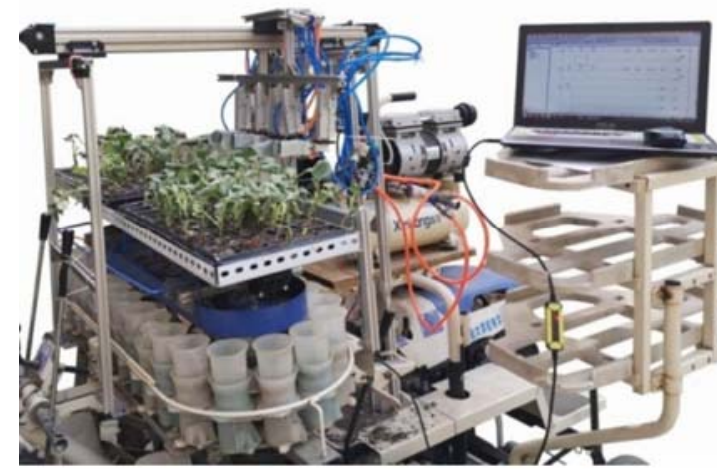

Figure 10 Performance test for the automated feeding device

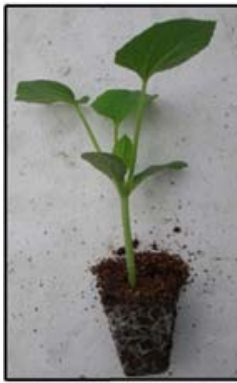

a. Cucumber

Figure 11 Three categories of plug seedlings

Table 1 Physical and mechanical properties for seedlings

\begin{tabular}{lccc}
\hline \multicolumn{1}{c}{ Characteristic parameters } & Cucumber & Pepper & Tomato \\
\hline Mean moisture content & $94.99 \%$ & $87.50 \%$ & $84.76 \%$ \\
Pressure resistance/N & 12 & 17 & 23 \\
Diameter at $5 \mathrm{~mm}$ from the root $\mathrm{mm}$ & 3.02 & 2.98 & 3.55 \\
Diameter at $25 \mathrm{~mm}$ from the root/mm & 2.96 & 2.90 & 3.42 \\
Mean number of leaves & 3.5 & 4.1 & 5.6 \\
\hline
\end{tabular}

\subsection{Results and analysis}

The test results were listed in Table 2. $\quad W$ is for the success rate, which referred to the seedlings picked up and dropped in the chain cups without damage, there were three "failed attempts" considered in the process of feeding seedlings (Figure 12), i.e. rate of missing seedling $W_{1}$, rate of stuck seedling $W_{2}$ and rate of injured seedling $W_{3}$. The successful rate $W$ was defined as follows:

$$
\begin{gathered}
W_{1}=\frac{N_{1}}{N} \times 100 \% \\
W_{2}=\frac{N_{2}}{N} \times 100 \% \\
W_{3}=\frac{N_{3}}{N} \times 100 \% \\
W=\left(1-W_{1}-W_{2}-W_{3}\right) \times 100 \%
\end{gathered}
$$

where, $N$ is the total number of seedlings for feeding; $N_{1}, N_{2}, N_{3}$ are the number of missing seedling, stuck seedling and injured seedling, respectively.
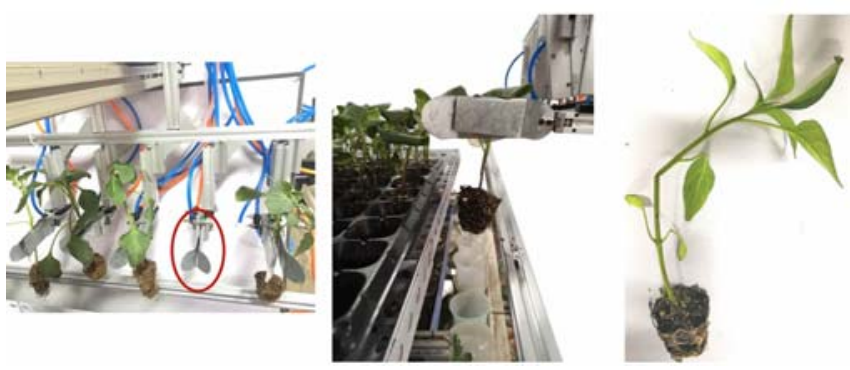

a. Missing seedling

b. Stuck seedling

c. Injured seedling

Figure 12 Examples of failures in feeding seedlings

It was observed in Table 2 that the success rate gradually declined along with the increase of feeding frequency. As to various vegetable seedlings, the tomato seedlings have a lower success rate, higher missing rate and higher stuck rate may because the strong stems, and more branches and leaves hinder the clamping of the end-effector (Table 1). Cucumber seedlings had the highest seedling injury rates, followed by pepper seedlings and then tomato seedlings, maybe because cucumber seedlings have higher moisture content and lower pressure resistance (Table 1). The result indicated that the feeding frequency and the physical and mechanical properties of different seedlings could affect the performance of the mechanism. Overall, the best performance emerged in the cucumber seedlings in 50-cell trays with the highest success rate of $88.00 \%$ at the feeding frequency of 6 groups $/ \mathrm{min}$, and the lowest success rate was $73.33 \%$ for the tomato seedlings in 105-cell trays at the feeding frequency of 12 groups/min, which implied that this feeding device can meet the requirements of the automated plug seedling transplanter.

Table 2 Performance test results of the automated feeding device

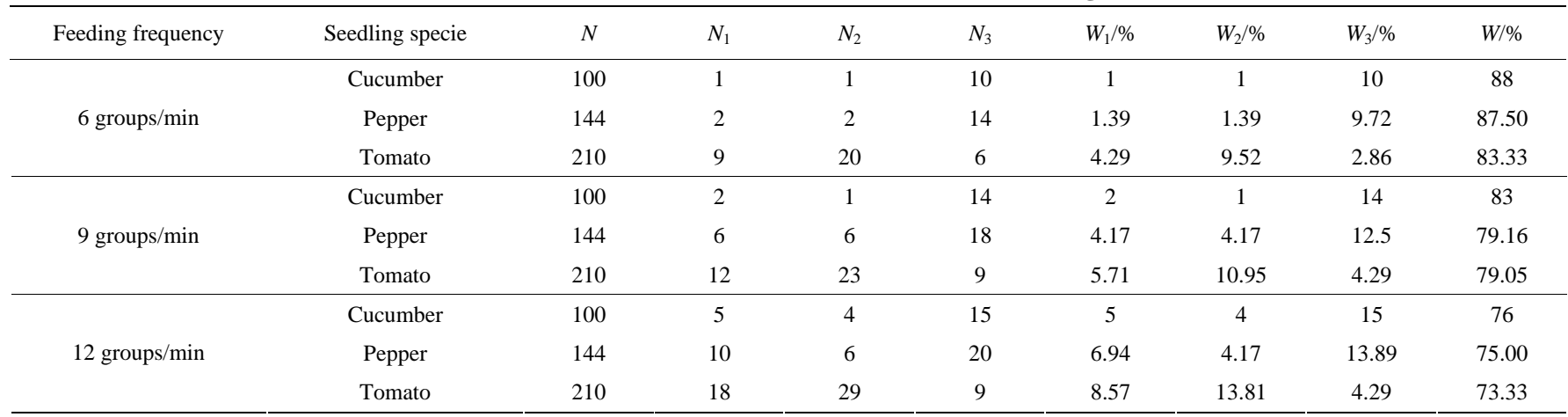


Although the automated feeding device was developed to expand its adaptability for various plug seedlings, the successful rate should be improved further to meet the practical application of high-speed transplantation. In the future research, the automated feeding device will be manufactured by professionals rather than by ourselves to obtain high precision and stability. A performance test will be also conducted using more plug seedlings with various conditions to investigate the defects of the device for improving it.

\section{Conclusions}

An automated seedling feeding device was designed and fabricated to pick up and drop the plug seedlings. Seedling delivery device as the first sub-system was equipped with a row of end-effectors. Its efficiency and adaptability for different trays could be improved by changing the number and spacing of the end effectors. A compact seedling tray conveyor was developed to transport the seedling trays by a reciprocating action. Integrated control system was constructed for each operation of the seedling feeding device on the basis of control sequence and motion planning, and the corresponding control program was designed to make all units work together. Test was conducted to evaluate the performances of the automated feeding device for various vegetable seedlings. And how the factors of feeding frequency and properties of three different seedlings affected the performance of the feeding device was analyzed. The results showed that the feeding device could be used for automatic field transplantation as a result of its strong adaptability to various plug seedlings.

\section{Acknowledgements}

This work was supported by the National Natural Science Foundation of China (Grant No. 31701325; 31671632), Green Farming and Mechanical Innovation Team of Fruit Harvesting under Soil, Ningbo Public Welfare Science and Technology Project (202002N3011).

\section{[References]}

[1] Du S, Yu J Z, Wang W B. Determining the minimal mulch film damage caused by the up-film transplanter. Advances in Mechanical Engineering, 2018; 10(3): 1-13.

[2] Zhang X, Wang C, Chen Y. Properties of selected biodegradable seedling plug-trays. Scientia Horticulturae, 2019; 249: 177-184.

[3] Feng Q, Zhao C, Jiang K, Fan P, Wang X. Design and test of tray-seedling sorting transplanter. Int J Agric \& Biol Eng, 2015; 8(2): $14-20$.

[4] Jin X, Li D Y, Ma H, Ji J T, Zhao K X, Pang J. Development of single row automatic transplanting device for potted vegetable seedlings. Int $\mathrm{J}$ Agric \& Biol Eng, 2018; 11(3): 67-75.

[5] Kumar G V P, Raheman H. Vegetable transplanters for use in developing countries-A review. International Journal of Vegetable Science, 2008; 14(3): 232-255.

[6] Jiang Z H, Zhou M C, Tong J H, Jiang H Y, Yang Y F, Wang A C, et al. Comparing an ant colony algorithm with a genetic algorithm for replugging tour planning of seedling transplanter. Computers and Electronics in Agriculture, 2015; 113: 225-233.
[7] Jiang Z H, Hu Y, Jiang H Y, Tong J H. Design and force analysis of end-effector for plug seedling transplanter. Plos One, 2017; 12(7): e0180229. doi: 10.1371/journal.pone.0180229.

[8] Suggs C W, Thomas T N, Eddington D L, Peel H B, Seaboch T R, Gore J W. Self-feeding transplanter for tobacco and vegetable crops. Applied Engineering in Agriculture, 1987; 3(2): 148-152.

[9] Armstrong E C, Hanacek W A, Spinetti T A. Automatic soil plug loader and feeder. United States Patent 4443151, USA, 1984.

[10] Ting K C, Giacomelli G A, Shen S J, Kabala W P. Robot workcell for transplanting of seedlings. Part II-End-effector development. Transactions of the ASABE, 1990; 33(3): 1013-1017.

[11] Ting KC, Giacomelli G A, Shen S J. Robot workcell for transplanting of seedlings part $\mathrm{i}$ - layout and materials flow. Transactions of the ASABE, 1990; 33(3): 1005-1010.

[12] Ni Y L, Jin C Q, Liu J. Design and experiment of system for picking up and delivering seedlings in automatic transplanter. Transactions of the CSAE, 2015; 31(23): 10-19. (in Chinese)

[13] Han C, Zhang X, Yang W, Yin W. Present status and analysis of dry-land auto-transplanting seedling technique. Journal of Agricultural Mechanization Research, 2011; 11: 238-240. (in Chinese)

[14] Han L, Mao H, Hu J, Tian K. Development of a doorframe-typed swinging seedling pick-up device for automatic field transplantation. Spanish Journal of Agricultural Research, 2015; 13(2): e0210. doi: 10.5424/sjar/2015132-6992.

[15] Hu J P, Yan X Y, Ma J, Qi C H, Francis K, Mao H P. Dimensional synthesis and kinematics simulation of a high-speed plug seedling transplanting robot. Computers \& Electronics in Agriculture, 2014; 107: 64-72.

[16] Zhang Z, Igathinathane C, Li J, Cen H, Flores P. Technology progress in mechanical harvest of fresh market apples. Computers and Electronics in Agriculture, 2020; 175: 105606. doi: 10.1016/j.compag.2020.105606.

[17] Zhang Z, Flores P, Igathinathane C, Naik D L, Ransom J K. Wheat lodging detection from UAS imagery using machine learning algorithms. Remote Sensing, 2020; 12(11): 1838 . doi: 10.3390/rs12111838.

[18] Fu L S, Majeed Y, Zhang X, Karkee M, Zhang Q. Faster R-CNN-based apple detection in dense-foliage fruiting-wall trees using RGB and depth features for robotic harvesting. Biosystems Engineering, 2020; 197: 245-256.

[19] Gao F, Fu L, Zhang X, Majeed Y, Li R, Karkee M, et al. Multi-class fruit-on-plant detection for apple in SNAP system using Faster R-CNN. Computers and Electronics in Agriculture, 2020; 176: 105634. doi: 10.1016/j.compag.2020.105634.

[20] Ye B L, Li L, Yu G H, Liu A, Cai D. Design and test on cam mechanism of seedling pick-up arm for vegetable transplanter for pot seedling. Transactions of the CSAE, 2014; 30(8): 21-29. (in Chinese)

[21] Han L H, Mao H P, Yan L, Hu J P, Huang W Y, Dong L L. Pincette-type end-effector using two fingers and four pins for picking up seedlings. Transactions of the CSAM, 2015; 46(7): 23-30. (in Chinese)

[22] Wu J, Zhang X, Jin X, Liu Z, Zhu L, Sun X, et al. Design and experiment on transplanter pot seedling disk conveying and positioning control system. Transactions of the CSAE, 2015; 31(1): 47-52. (in Chinese)

[23] Yang Q Z, Xu L, Shi X Y, Ibrar A, Mao H P, Hu J P, et al. Design of seedlings separation device with reciprocating movement seedling cups and its controlling system of the full-automatic plug seedling transplanter. Computers and Electronics in Agriculture, 2018; 147: 131-145.

[24] Zhou M L, Hua Z Y, Wang J Y, Wang L, Zhao Y, Yin D Q. New type of transverse moving box mechanism for pot seedling transplanting machine. Int J Agric \& Biol Eng, 2018; 11(2): 70-75.

[25] Yu Y X, Liu J K, Ye B L, Yu G H, Jin X J, Sun L, et al. Design and experimental research on seedling pick-up mechanism of planetary gear train with combined non-circular gear transmission. Chinese Journal of Mechanical Engineering, 2019; 32(1): 1-13. (in Chinese) 